\title{
Erratum to: The Association of Religious Affiliation and Body Mass Index (BMI): An Analysis from the Health Survey for England
}

\section{Deborah Lycett}

Published online: 23 December 2014

(C) Springer Science+Business Media New York 2014

\section{Erratum to: J Relig Health DOI 10.1007/s10943-014-9975-3}

The below acknowledgement text was not included in the original publication.

\section{Acknowledgments}

The author thanks all the staff at the National Centre for Social Research and University College London Department of Epidemiology and Public Health, the Information Centre for Health and Social Care and the UK Data Archive for conducting, funding and archiving the data so that it is accessible to others. These parties bear no responsibility for the further analysis or interpretation of their data as presented in this paper.

The online version of the original article can be found under doi:10.1007/s10943-014-9975-3.

D. Lycett $(\bowtie)$

Faculty of Health and Life Sciences, Coventry University, Coventry CV1 5FB, UK

e-mail: deborah.lycett@coventry.ac.uk 